\title{
Chinese Birch Pollen Allergy and Immunotherapy in Mice
}

\author{
Zhijuan Xie ${ }^{1}$ and Jia Yin ${ }^{1,2}$
}

\begin{abstract}
Birch pollen allergy is a common cause of spring pollinosis in China. However, there is little research on birch pollen allergen in China and only the major allergen (Bet v 1) has been fully characterized. Chinese birch pollen-induced airway inflammation models in BALB/c mice were developed and administered subcutaneous immunotherapy (SCIT). $\mathrm{BALB} / \mathrm{c}$ mice were sensitized subcutaneously on days 1,8 , and 15 with $25 \mu \mathrm{g} / \mu \mathrm{L}$ birch pollen extract. On days 24-26, the mice were challenged with $0.1 \%$ birch pollen aerosol. To investigate the efficacy of SCIT, mice were subcutaneously injected $0.3 \mathrm{mg}$ birch pollen extract (BPE) with or without being adsorbed to alum. Airway hyper-responsiveness (AHR) to methacholine and immunological parameters was detected. Western blot analysis was applied with mice serum and mass spectrometry was used to identify the IgE-binding bands in birch pollen. Compared with PBS group, birch pollen sensitization and challenge BALB/c mice developed AHR, and IL4, IL5, IL6, IL10, and IL17 were significantly higher. Mice sensitized by birch pollen showed increased plasma levels of anti-BPE IgE, IgG1, and IgG2a. Histologic analyses showed that mice had peribranchial infiltration of inflammatory cells and mucosal hyperplasia. After SCIT, allergic symptoms effectively alleviated and kept for a long time. Interestingly, mice serum pool showed strong reactions to $70-\mathrm{kDa}$ proteins. Mass spectrometry data suggests that the $70-\mathrm{kDa}$ protein belongs to the HSP 70 family. SCIT inhibited the inflammatory response in the long term and a $70-\mathrm{kDa}$ protein potentially belonging to the HSP 70 family plays a significant role in Chinese birch pollen-induced mice model.
\end{abstract}

KEY WORDS: Chinese birch pollen allergy; birch pollen allergen; mice model; asthma; 70-kDa allergen.

\section{INTRODUCTION}

Birch pollen is one of the most important spring pollens in north of China. In Europe, $70 \%$ of birch pollen allergy patients have accompanying varying degrees of food allergy [1]. Their symptoms are mainly shown after ingesting birch

\footnotetext{
${ }^{1}$ Department of Allergy, Peking Union Medical College Hospital, Chinese Academy of Medical Sciences and Peking Union Medical College, No. 1 Shuai Fu Yuan, Wang Fu Jing Street, Beijing, 100730, China

${ }^{2}$ To whom correspondence should be addressed at Department of Allergy, Peking Union Medical College Hospital, Chinese Academy of Medical Sciences and Peking Union Medical College, No. 1 Shuai Fu Yuan, Wang Fu Jing Street, Beijing, 100730, China. E-mail: doctoryinjia@163.com
}

pollen-related foods [2], at least in part because of the crossreaction between Bet $\mathrm{v} 1$ homologous protein in food and the major allergen Bet $\mathrm{v} 1$ in birch pollen, including apple (Mal d 1), cherry (Pru av. 1), pear (Pyr c 1), hazelnut (Cor a 1), celery (Api g 1), carrot (Dau c 1), soybean (Gly m 4), peanut (Ara h 8), jackfruit, and kiwi (Act d 8) [3].

Subcutaneous immunotherapy (SCIT) is the only way to effectively control allergy symptoms and it can change the natural courses from allergic rhinitis to allergic asthma [4-7]. They demonstrated that the mechanism of SCIT is largely related to the reduction of Th2-related cytokines (IL4 and IL5) and Th17-related cytokines (IL17). It is also thought that SCIT induces the production of protective antibodies IgG4 (IgG2a in mice) to inhibit mast cell 
activation $[8,9]$. Regulatory $\mathrm{T}$ cells (Treg) suppress the allergic inflammation by producing IL10 and TGF- $\beta$ in SCIT. IL-10 suppresses T cell responses, promotes IgG4 production, and suppresses IgE production [10]. TGF- $\beta$ is required for Treg differentiation. Moreover, IL-6 may regulate the balance between Th17 cells and Treg cells [11]. Adjuvants, especially the alum, play a central role in costimulating immune cells in the SCIT, which also lead to local or systemic adverse effects.

Seven allergens in birch pollen have been included in the official allergen list of the World Health Organization and International Union of Immunological Societies (WHO/IUIS) allergen nomenclature subcommittee (www.allergen.org), named sequentially as Bet $\mathrm{v} 1$ through Bet $v$ 7. Research is often biased toward a single major allergen (Bet v 1) [12]. Panallergens are ubiquitous with broad cross-sensitization and underlie certain pollen-food or plant-food syndromes [13]. However, there is little research conducted on birch pollen allergen in China.

In this study, it is the first time to establish an allergy murine model with Chinese birch pollen and observe the long efficacy of SCIT in mice. We also hypothesized that SCIT without adjuvant (alum) remains efficient in mice.

\section{MATERIALS AND METHODS}

\section{Mice}

Female BALB/c mice, at 5-6 weeks of age, were purchased from Beijing Vital River Laboratory Animal Technology Co, Beijing, China. All of the mice were given a 7-day period acclimate. The animals were kept under Specific Pathogen Free (SPF) laboratory conditions in the Center for Animal Experiments of Peking Union Medical College Hospital. The institutional animal ethics committee approved all experiments.

\footnotetext{
Allergens

Standard birch pollen extracts (BPE) were provided by the department of allergy, Peking Union Medical College Hospital, Beijing, China. These can be used for patients in clinics. The protein concentration was determined using the Pierce BCA Protein Assay Kit (Thermo Fisher Scientific, Waltham, Mass). The major protein Bet v1 of birch pollen extract was determined by a Bet $\mathrm{v} 1$ ELISA kit (4 e10 b10/2) (Indoor Biotechnologies Inc., Cardiff, UK).
}

\section{Study Design}

\section{Allergen Sensitization}

$\mathrm{BALB} / \mathrm{c}$ mice were sensitized subcutaneously on days 1,8 , and 15 with $25 \mu \mathrm{g} / \mu \mathrm{L}$ birch pollen extracts, which contained $5 \mu \mathrm{g}$ Bet $\mathrm{v} 1$, absorbed to $100 \mu \mathrm{L}$ alum (Imject Alum, Thermo, USA) by Eppendorf plus. On days 24-26, the mice were challenged with $0.1 \%$ birch pollen extract aerosol. After 1 day, airway hyper-responsiveness (AHR) to methacholine was assessed. The control group were sensitized subcutaneously with Phosphate Buffered Saline (PBS) and challenged with PBS. (Fig. 1A).

\section{SCIT Treatment}

The long-term treatment group: mice were subcutaneously injected with $0.3 \mathrm{mg}$ BPE adsorbed to $0.1 \mathrm{mg}$ alum on days $32,39,46,53,60,67,74$, and 81 . On days $88-90$, the mice were re-challenged for three consecutive days with $0.1 \%$ BPE aerosol, 30 min per day, as before. After 1 day, AHR to methacholine was assessed. After $24 \mathrm{~h}$, the mice were euthanized for evaluation using the immunological parameters. The protocol was described by past studies [14] (Fig. 2A).

The short-term treatment group: mice were subcutaneously injected with $0.3 \mathrm{mg}$ birch pollen extract (BPE) without being adsorbed to alum on days $32,34,36,38$, 40, 42,44 , and 46 . Then, the mice were challenged with $0.1 \%$ BPE aerosol. AHR to methacholine was evaluated on day 56. The next day, the mice were euthanized and evaluated (Fig. 2B).

\section{Observation}

In order to evaluate the long-term efficacy of SCIT, mice were kept without any treatment on days $92-126$ after receiving the long-term treatment. Then, the mice were challenged again for another three consecutive days. After 1 day, AHR to methacholine was assessed. After $24 \mathrm{~h}$, the mice were euthanized and serum was collected (Fig. 3A). The immunological parameters were compared with the long-term treatment.

In the treatment phase, the PBS treatment group were sensitized, challenged, and non-treated mice. It means the mice were sensitized subcutaneously with BPE, challenged with BPE, and received PBS treatment.

\section{Airway Hyper-responsiveness (AHR) Measurement}

Airway responsiveness was measured in mice $24 \mathrm{~h}$ after the final birch pollen challenge with a Buxco 
a

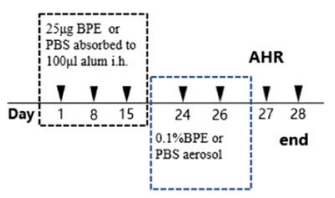

b AHR

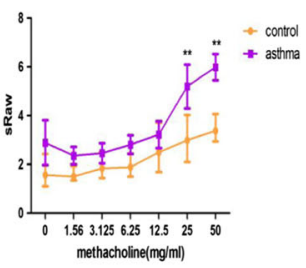

c Cytokines in BALF
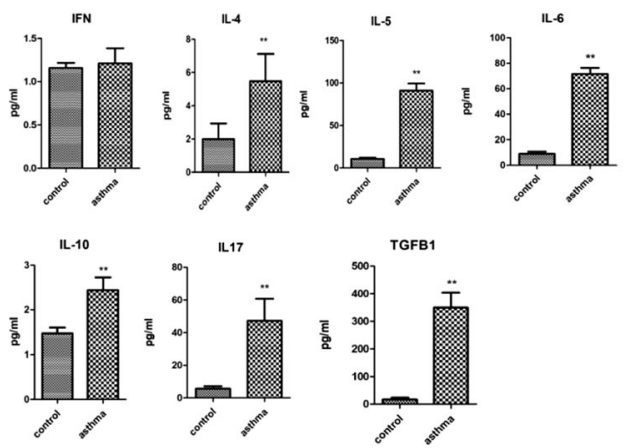

d Birch-pollen-specific immunoglobulins
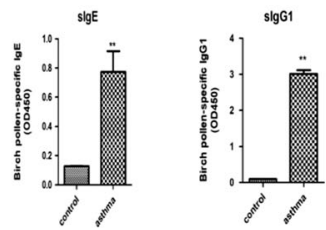

e Lung tissue eosinophilia and mucus production
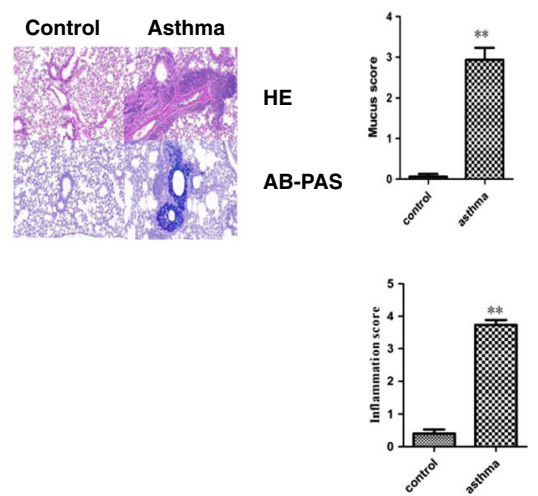

Fig. 1. Allergen sensitization. A Timeline for female mice with BPE. BALB/c mice were sensitized subcutaneously with $25 \mu \mathrm{g} / \mu \mathrm{BPE}$ or PBS on days 1,8 , and 15. On days 24-26, the mice were challenged by nebulization with $0.1 \%$ birch pollen aerosol or PBS aerosol. After 1 day, AHR to methacholine was assessed. After $24 \mathrm{~h}$, mice were euthanized. B Airway hyper-reactivity to methacholine is shown on day 27. C Cytokines in BALF are shown. D Birch pollenspecific immunoglobulins (sIgE, sIgG1, sIgG2a) are measured by using ELISA. E Lung tissue eosinophilia and mucus production are shown. Lung specimens were stained with hematoxylin and eosin $(\mathrm{H} \& \mathrm{E})$ and $\mathrm{AB}-\mathrm{PAS}$ staining. Data are shown as means $\pm \mathrm{SD}$ from 8 to 10 mice per group, ** represents the asthma group $v s$. the control group, $P<0.01$; * represents the asthma group $v s$. the control group, $P<0.05$.

FinePointe System for noninvasive airway measurement (Buxco, Wilmington, USA) according to the manufacturer's instructions. Mice were given 5 min to acclimate and then exposed to aerosolized PBS to set a baseline value, followed by increasing concentrations of $100 \mu \mathrm{l}$ aerosolized methacholine $(3.125,6.25,12.5,25$, and $50 \mathrm{mg} / \mathrm{mL}$ in PBS for $1 \mathrm{~min}$; Sigma-Aldrich, German). The specific airway resistance (sRAW) were measured after each methacholine aerosol application by the noninvasive airway device.

\section{Cytokine Evaluation}

In brief, the bronchial tube was lavaged three times with $0.8 \mathrm{~mL}$ of PBS via a tracheal cannula and then the bronchoalveolar lavage fluid (BALF) was recovered. The BALF were centrifuged at $4000 \mathrm{RPM}$ for $10 \mathrm{~min}$ at $4^{\circ} \mathrm{C}$. The supernatant was stored at $-80{ }^{\circ} \mathrm{C}$ until the measurement of cytokines. IL-4, IL-10, IL-17A, and IFN- $\gamma$ in the supernatant of BALF were determined by the MILLIPLEX MAP Mouse Cytokine/Chemokine Magnetic Panel
(Millipore, Billerica, USA) according to manufacturer's instructions. The results were analyzed with the Bio-Plex System (Bio-Rad Laboratories, Hercules, USA). Values were reported in pg/ml. IL-5, IL-6, and TGF- $\beta$ levels in the BALF were measured with ELISA kits (eBioscience, San Diego, USA), according to the protocol recommended by the manufacturer.

\section{Birch Pollen Specific Serum IgE, IgG1, and IgG2a}

Serum levels of birch pollen $\operatorname{IgE}, \operatorname{IgG} 1$, and $\operatorname{IgG} 2 \mathrm{a}$ were measured by Enzyme-Linked Immunosorbent Assay (ELISA). Briefly, 96-well plates (Thermo Fisher Scientific, Waltham, USA) were coated with $100 \mu \mathrm{l} /$ well birch pollen extract $(0.05 \mathrm{mg} / \mathrm{mL})$ diluted with PBS overnight at $4{ }^{\circ} \mathrm{C}$. Then, washed the plate for three times, added $200 \mu \mathrm{l}$ blocking buffer (5\% skim milk in PBS) to incubate for $2 \mathrm{~h}$ at room temperature. After another three washes, serum samples were diluted 1/200 for IgG1, 1/200 for $\operatorname{IgG} 2 \mathrm{a}$, and $1 / 10$ for IgE with PBS and $100 \mu \mathrm{l} /$ well was added to the plate overnight at $4{ }^{\circ} \mathrm{C}$. The serum samples were washed 


\section{a Long-term treatment group}

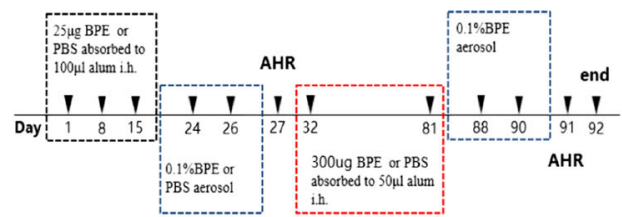

\section{b Short-term treatment group}

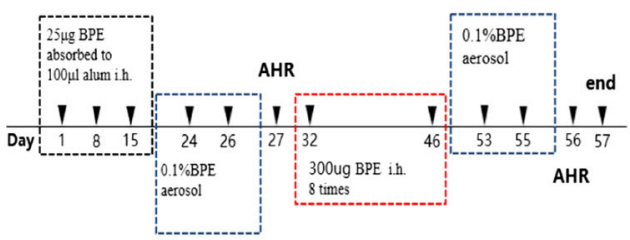

c AHR
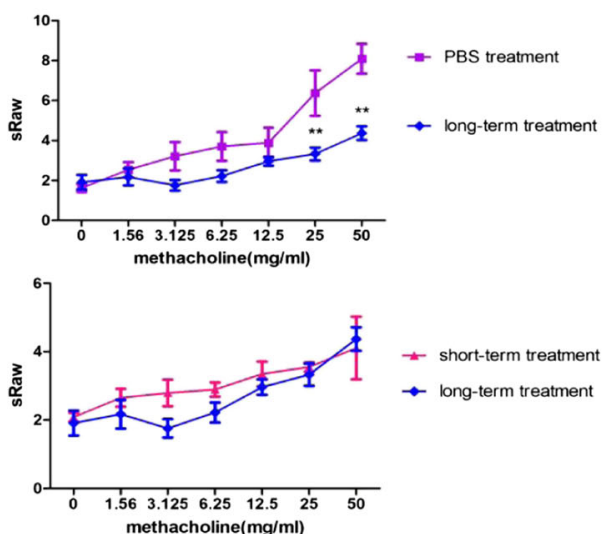

\section{d Cytokines in BALF}

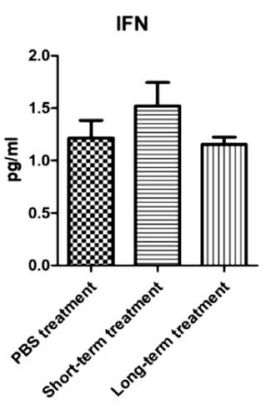

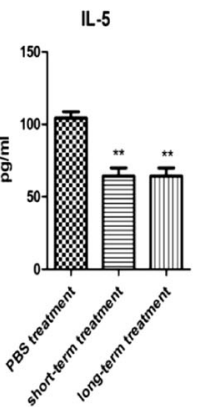

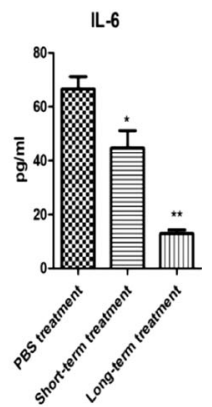

Fig. 2. SCIT provides therapeutic benefit. A Timeline for the long-term treatment group. BPE was injected subcutaneously on days 1,8 , and 15 . On days 24 26, the mice were challenged with $0.1 \%$ birch pollen aerosol. After 1 day, AHR to methacholine was assessed. Mice were subcutaneously injected with $0.3 \mathrm{mg}$ BPE adsorbed to $0.1 \mathrm{mg}$ alum on days $32,39,46,53,60,67,74$, and 81 . On days 88-90, the mice were re-challenged for three consecutive days with $0.1 \%$ birch pollen extract aerosol, $30 \mathrm{~min}$ per day, as before. After 1 day, AHR to methacholine was assessed. After $24 \mathrm{~h}$, the mice were euthanized for evaluation using the immunological parameters. The PBS treatment group: BPE was injected subcutaneously on days 1,8 , and 15 . On days $24-26$, the mice were challenged with $0.1 \%$ birch pollen aerosol. After 1 day, AHR to methacholine was assessed. Mice were subcutaneously injected with PBS adsorbed to $0.1 \mathrm{mg}$ alum on days $32,39,46,53,60,67,74$, and 81 . On days $88-90$, the mice were re-challenged for three consecutive days with $0.1 \%$ birch pollen extract aerosol, $30 \mathrm{~min}$ per day. After 1 day, AHR to methacholine was assessed. After $24 \mathrm{~h}$, the mice were euthanized for evaluation using the immunological parameters. B Timeline for the short-term treatment group. After allergen sensitization, mice were subcutaneously injected with $0.3 \mathrm{mg}$ birch pollen extract (BPE) without being adsorbed to alum on days $32,34,36,38,40,42,44$, and 46. Then, the mice were challenged as described above. AHR to methacholine was evaluated on day 56. The next day, the mice were euthanized and evaluated. C Airway hyper-reactivity to methacholine is shown. The PBS treatment group and the long-term treatment group; the short-term treatment group and the long-term treatment group. D Cytokines in BALF are shown. E Birch pollen specific immunoglobulins (sIgE, sIgG1, sIgG2a) are measured by using ELISA. F Lung tissue eosinophilia and mucus production are shown. Lung specimens were stained with hematoxylin and eosin $(\mathrm{H} \& \mathrm{E})$ and $\mathrm{AB}-\mathrm{PAS}$ staining. Data are shown as means $\pm \mathrm{SD}$, ** represents the short-term treatment group and the long-term treatment group $v$ s. the PBS treatment group, $P<0.01$; * represents the short-term treatment group and the long-term treatment group $v s$. the PBS treatment group, $P<0.05$. 
e Birch-pollen-specific immunoglobulins
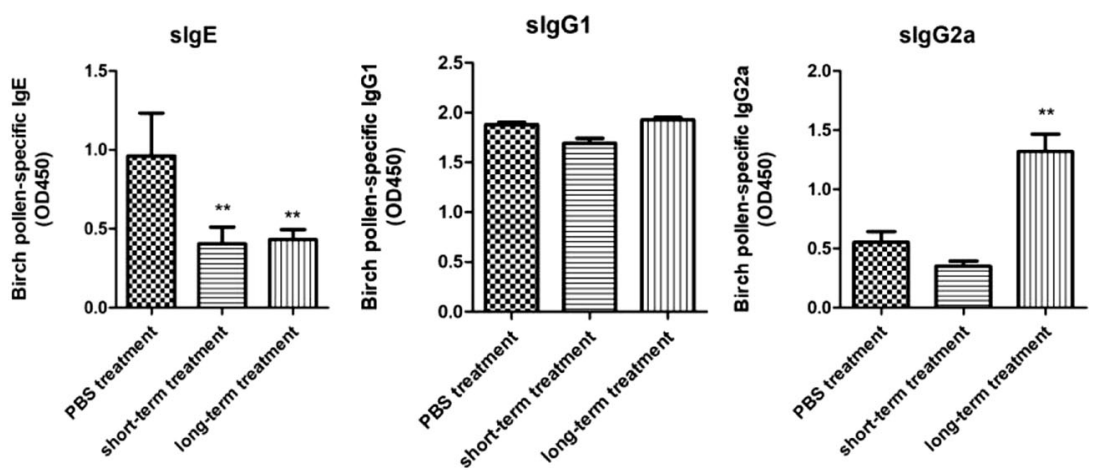

\section{f Lung tissue eosinophilia and mucus production}
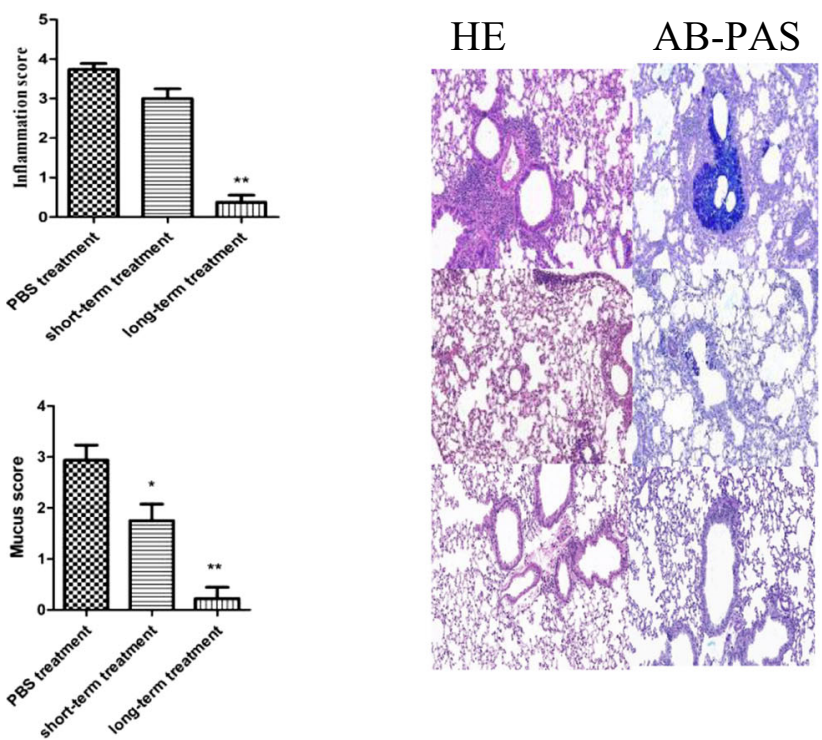

PBS treatment group

Short-term group

Long-term group

Fig. 2. (continued)

again and the second antibodies were added in 1/1000 with PBS for $2 \mathrm{~h}$ at room temperature. Finally, the HRP was added and the plates were read at $450 \mathrm{~nm}$ by an ELISA plate reader. The second antibodies were Rat Anti-Mouse IgE (HRP) (ab99574, Abcam, Cambridge, UK), Goat Anti-Mouse IgG1 heavy chain (HRP) (ab97240, Abcam, Cambridge, UK), and Goat Anti-Mouse IgG2a heavy chain (HRP) (ab97245, Abcam, Cambridge, UK). All experiments were performed in duplicates.

\section{Histological Analysis}

Mice lungs were fixed with $10 \%$ formaldehyde and embedded in paraffin. Lung tissues were then cut into micro-slices, and stained with hematoxylin and eosin (H\&E) or Alcian blue-periodic acid-Schiff (AB-PAS) for histological analysis. Inflammatory scores and mucus scores were graded $(0=$ no inflammation to 4$)$ as past studies described $[15,16]$.

\section{SDS-PAGE and Western Blot}

BPE was absorbed to NuPAGE LDS Sample Buffer (Invitrogen, Carlsbad, CA, USA). The final concentration was adjusted to $1 \mathrm{mg} / \mathrm{ml}$ with PBS. Ten microliters of BPE was used for Western blotting experiments. Birch pollen protein was fractioned by sodium dodecyl sulfatepolyacrylamide gel electrophoresis (SDS-PAGE) 


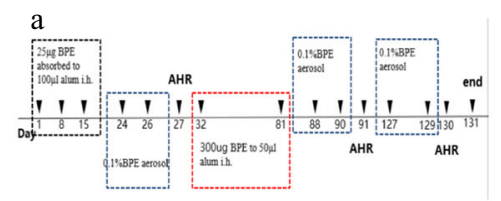

b AHR

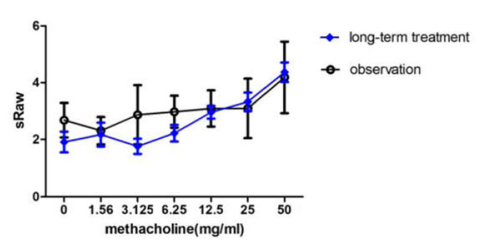

c Cytokines in BALF

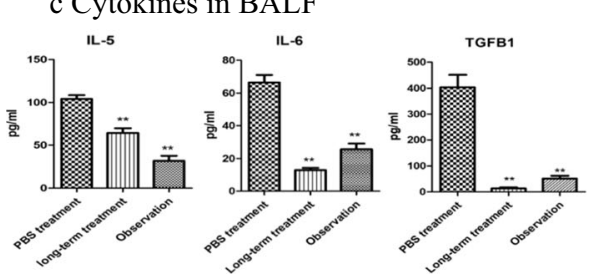

d Birch-pollen-specific immunoglobulins

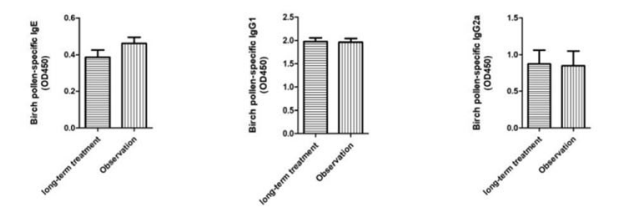

e Lung tissue eosinophilia and mucus production

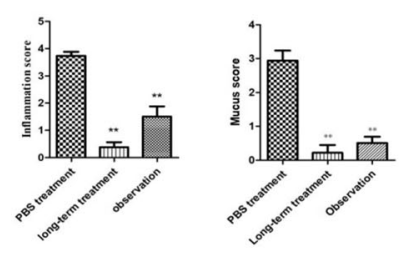

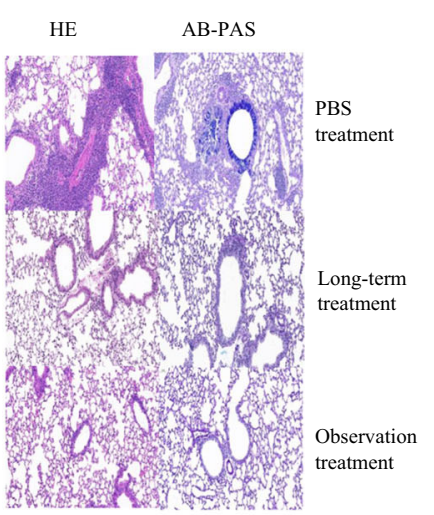

Fig. 3. Long-term efficacy of SCIT. A Timeline for observation group. After the long-term treatment, mice were kept without any treatment on days $92-126$. Then, the mice were challenged again for another three consecutive days. After 1 day, AHR to methacholine was assessed. After $24 \mathrm{~h}$, the mice were euthanized and serum was collected. B Airway hyper-reactivity to methacholine is shown; the observation group vs. the long-term treatment group. C Cytokines in BALF are shown. D Birch pollen specific immunoglobulins (sIgE, sIgG1, sIgG2a) are measured by using ELISA. E Lung tissue eosinophilia and mucus production are shown. Lung specimens were stained with hematoxylin and eosin (H\&E) and AB-PAS staining. Data are shown as means \pm SD, $* *$ represents the observation group $v s$. the long-term treatment group, $P<0.01$; * represents the observation group $v s$. the long-term treatment group, $P<0.05$.

(Invitrogen, Carlsbad, CA, USA). Then, the gel was transferred onto a polyvinylidene fluoride (PVDF) membrane. The membrane was treated with 5\% skim milk for $2 \mathrm{~h}$ to block nonspecific binding and incubated with the mice serum pool overnight at $4{ }^{\circ} \mathrm{C}$ (mice's serum pool was diluted tenfold with 5\% skim milk). Then the membrane was incubated with 1:1000 the second antibodies rat antimouse IgE (HRP) (Abcam, Cambridge, UK) for $1 \mathrm{~h}$ at room temperature. The procedure is described in detail by Lämmli [17].

\section{Mass Spectrometry}

SDS-PAGE gels were selected from the Coomassiestained gels. Each was covered with $100 \mu \mathrm{L}$ of $50 \mathrm{mM}$ ammonium bicarbonate (ABC) buffer in $50 \%$ acetonitrile $(\mathrm{ACN})$ with $50 \mathrm{mM}$ dithiothreitol (DTT). Each gel spot was covered with $100 \mu \mathrm{L}$ of $50 \mathrm{mM}$ ammonium bicarbonate $(\mathrm{ABC}) / 50 \% \mathrm{ACN}$ containing $50 \mathrm{mM}$ iodoacetamide (IAA) and sonicated for $5 \mathrm{~min}$. After $15 \mathrm{~min}$, the supernatant was discarded and replaced with $100 \mu \mathrm{L}$ of $50 \mathrm{mM}$ $\mathrm{ABC} / 50 \% \mathrm{ACN}$ containing $50 \mathrm{mM}$ DTT. The supernatant was discarded, and the samples were again sonicated for $5 \mathrm{~min}$ in $100 \mu \mathrm{L}$ of HPLC/MS-grade water. The water was discarded, and the samples were again sonicated for $5 \mathrm{~min}$ in $100 \mu \mathrm{L}$ of $\mathrm{ACN}$. The ACN was discarded, and the sample-containing microtubes were air-dried to remove the remaining ACN. Next, trypsin in $10 \mu \mathrm{L}$ of $50 \mathrm{mM}$ $\mathrm{ABC}$ was added to each sample, and the samples were incubated overnight at $37{ }^{\circ} \mathrm{C}$ followed by the addition of trifluoroacetic acid (TFA) and ACN to final concentrations of $1 \%$ and $30 \%$, respectively. Each sample was assayed in triplicate. LC-MS/MS analysis was performed on a QExactive mass spectrometer (Thermo Fisher Scientific, Waltham, MA, USA) equipped with a nano-liquid chromatography system (Thermo Scientific EASY-nLC 1000 System, Waltham, MA, USA).

\section{Database Searching and Protein Identification}

The raw data were extracted by ProteoWizard version 3.0.8789. All MS/MS samples were analyzed using Mascot (version 2.6.0). Mascot was set up to search the SWISS-PROT 20171211 database assuming the digestion 
enzyme as trypsin. Mascot was searched with a fragment ion mass tolerance of $0.020 \mathrm{Da}$ and a parent ion tolerance of 10.0 PPM. Carbamidomethyl of cysteine were specified in Mascot as fixed modifications. Oxidation of methionine was specified in Mascot as variable modifications. Scaffold $\mathrm{Q}+$ (version Scaffold_4.6.2) was used. Protein identifications were accepted if they could be established at greater than $90.0 \%$ probability to achieve a false discovery rate (FDR) less than $10.0 \%$ and contained at least one unique peptide.

\section{Statistical Analyses}

Experimental data are presented as mean \pm SD. Line graphs were used to show measurement metrics. Statistical differences were assessed with Mann-Whitney $U$ test. We performed our analyses using the statistical software SPSS19.0 and GraphPad prism 5.0. $P$ values $<0.05$ were considered statistically significant.

\section{RESULTS}

\section{SDS-PAGE Analysis}

For further characterization of the birch pollen protein, we used SDS-PAGE to explore Chinese birch pollen extract. Birch pollen extracts (BPE) showed multiple protein bands with an apparent molecular mass ranging from 10 to $100 \mathrm{kDa}$ and protein bands showed especially clear at $17 \mathrm{kDa}, 28 \mathrm{kDa}, 36 \mathrm{kDa}$ and $70 \mathrm{kDa}$ (Fig. 4A).

\section{Birch Pollen-Induced Mice Model}

Compared with a PBS control group, BPE sensitized and challenged BALB/c mice (the asthma group) developed AHR, especially at methacholine concentrations of $25 \mathrm{mg} / \mathrm{mL}$ and $50 \mathrm{mg} / \mathrm{mL}(P<0.01)$ (Fig. 1B). In BALF, Th2-related cytokines IL-4, IL-5, and IL-6; Th17-related cytokines IL-17; and Treg-related IL-10 and TGF- $\beta$ were significantly higher in the asthma group than in the control group, while Th1-type-related IFN- $\gamma$ showed no difference (Fig. 1C). As described above, mice sensitized by BPE demonstrated increased plasma levels of anti-BPE IgE, IgG1, and IgG2a (Fig. 1E). Histologic analyses showed that asthma mice lung had peribronchial infiltration of inflammatory cells and mucosal hyperplasia (Fig. 1F).

\section{Birch Pollen with or Without Adjuvant Suppresses Airway Allergy Inflammation}

Recent studies have shown that SCIT may effectively alleviate allergy symptoms [18]. To elucidate the efficacy of SCIT, we administered Chinese birch pollen extract for the long-term treatment group. Also, we questioned whether birch pollen without adjuvant (alum) is sufficient to trigger a series of immune responses. We administered another short-term immunotherapy.

Interestingly, AHR relieved significantly in the long-term immunotherapy group than PBS treatment group (Fig. 2C). There were no differences between two groups in AHR (Fig. 2C). Compared to the PBS treatment group, the concentrations of Th2-typerelated cytokines IL-4, IL-5, and IL-6 and Th17 cytokines IL-17 showed a significant reduction in the BALF in both groups. However, Treg-related IL-10 and TGF- $\beta$ showed no difference in BALF only in the long-term immunotherapy group. This may be due to the limitation of the treatment period. There was no difference in Th1-type-related IFN- $\gamma$ between groups (Fig. 2D) BPE-specific IgE in the short-term treatment group was lower than the PBS treatment group just as the long-term treatment group, but it was not adequate to increase the concentration of protective antibody BPE-specific IgG2a. The long-term treatment group had a higher level of BPE-specific IgG2a than other groups (Fig. 2F). Pathological inflammatory scores and mucus scores decreased significantly in long-term treatment group (Fig.2G).

\section{SCIT Provides Long-Term Therapeutic Benefit}

The above observation led us to conclude that SCIT may inhibit airway inflammation effectively, resulting in the alleviation of the Th2-type and Th17-type immune response, but there is no evidence whether the efficacy will last for a long time. After the long-term treatment, some of the mice did not die and instead they received no treatment for 5 weeks. Then, the remaining mice were exposed to BPE aerosols again, the efficacy of SCIT remained (Fig. 3B). There is no difference between the long-term group and the observation group. However, the two groups are both significantly lower than the PBS treatment group in the level of cytokines, birch pollen specific immunoglobulins, and mucus score (Fig. 3C-F). 
a

$1 \quad M$

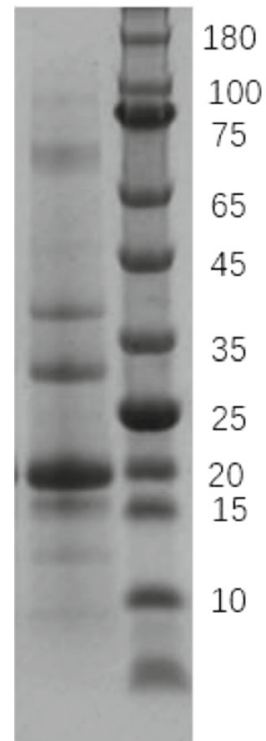

b

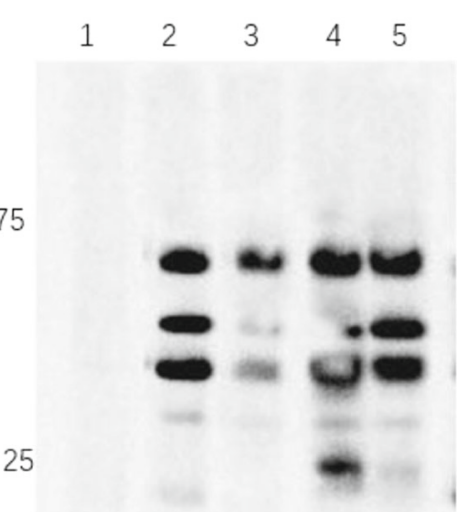

Fig. 4. SDS-PAGE and Western blot analysis. A Representative image of SDS-PAGE. Lane M: molecular weight markers (180 kDa, $100 \mathrm{kDa}, 75 \mathrm{kDa}, 65 \mathrm{kDa}$, $45 \mathrm{kDa}, 35 \mathrm{kDa}, 25 \mathrm{kDa}, 20 \mathrm{kDa}, 15 \mathrm{kDa}, 10 \mathrm{kDa}$ ). Lane 1: 10- $\mu$ l protein profiles of birch pollen extracts. B Western blot analysis of the antigen-binding characteristics of serum specific IgE antibodies with birch pollen using sera. Lane 1: immune-blotting patterns of protein extracts with the PBS-sensitized and challenged mice serum (negative control). Lane 2: immune-blotting patterns of protein extracts with the BPE-sensitized and challenged but received PBS treatment mice serum. Lane 3: immune-blotting patterns of protein extracts with the short-term treatment group mice serum. Lane 4: immune-blotting patterns of protein extracts with the long-term treatment group mice serum. Lane 5: immune-blotting patterns of protein extracts with the observation group mice serum.

\section{Serum IgE Reactivity in Mice}

Using serum from all groups of mice, IgE-binding proteins ranged from 10 to $100 \mathrm{kDa}$. The PBS-sensitized and challenged mice reacted no pollen protein, (Fig. 4B, Lane 1); the BPE asthma mice reacted strongly to 36,45 , and $70 \mathrm{kDa}$ while reacted weakly to 17 and $28 \mathrm{kDa}$ (Fig. 4B, Lane 2). The short-term treatment group mice (Fig. 4B, Lane 3), the long-term treatment group mice (Fig. 4B, Lane 4), and the observation group mice (Fig. 4B, Lane 5) all reacted to the $70-\mathrm{kDa}$ bands.

\section{Mass Spectrometry}

To identify the 70-kDa protein in Chinese birch pollen extracts, bands were numbered, excised, in-gel digested with trypsin, and analyzed by LC-MS/MS. There are three technical repeats for each sample. Taking into account the peptide segment of the mass spectrum, we designated five proteins in database searches, as summarized in Table 1 . The proteins included Luminal-binding protein, Heat shock 70-kDa proteins, probable pectin esterase, glucose-6-phosphate isomerase 1 , and UDP-sugar pyrophosphorylase. The spectra of these isolated proteins from birch pollen are shown in Fig. 5A-E.

\section{DISCUSSION}

This is the first time that Chinese birch pollen immunotherapy was studied in mice [14, 19]. Adjuvants have been widely used to increase the immunogenicity of accompanying antigen in treating allergic diseases. Alum, the first-generation adjuvant, plays a significant role in SCIT. However, the period of BPE SCIT currently containing adjuvants (alum) is too long, leading to patients being reluctant to receive specific immunotherapy. Many adverse events of adjuvants have been reported such as chronic aluminum toxicity.

In addition to the long-term treatment group, the short-term non-adjuvant therapy group was also used in our study. The results suggest that, in the long-term treatment group, the Th2 immune response and Th17-related inflammation can be inhibited and the production of IgG blocking antibodies can be induced, thus alleviating the symptoms. Interestingly, in the short-term treatment group, there was a sufficient suppression of airway inflammation in the mice. The short-term treatment is a considerate choice for patients who are concerned about the side effects of the adjuvant (alum) in receiving BPE SCIT, but this needs further clinical studies. 
Table 1. The 70-kDa Protein and Peptide Sequences in Birch Pollen Extracts Identified by Mass Spectrometry

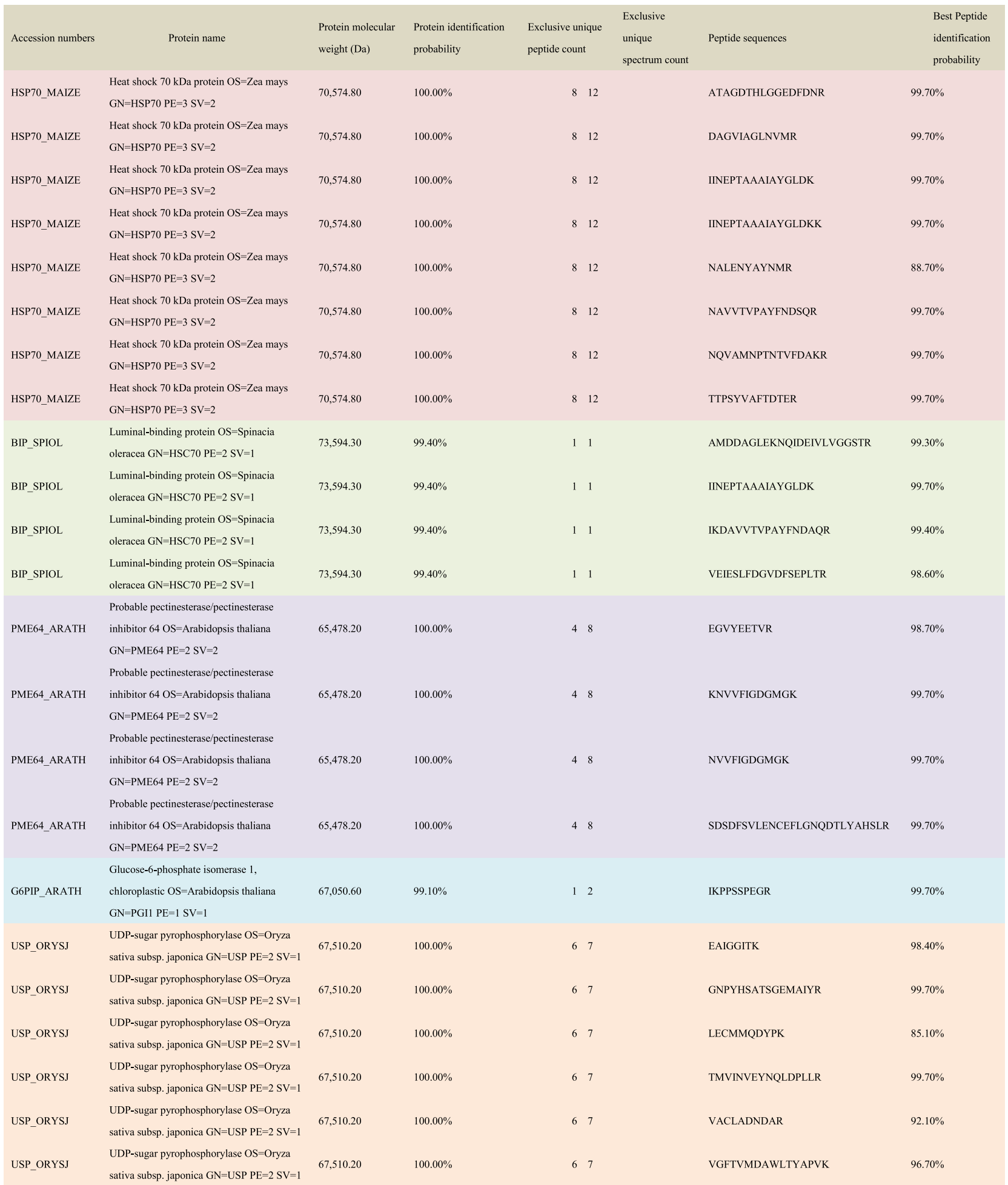


a

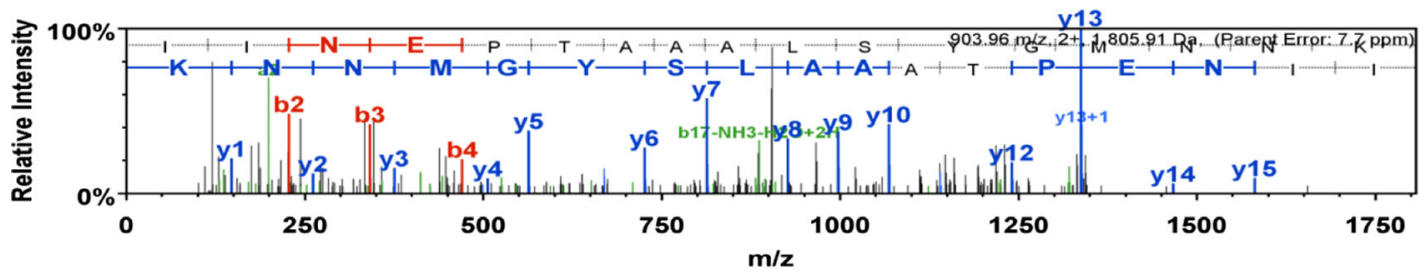

b

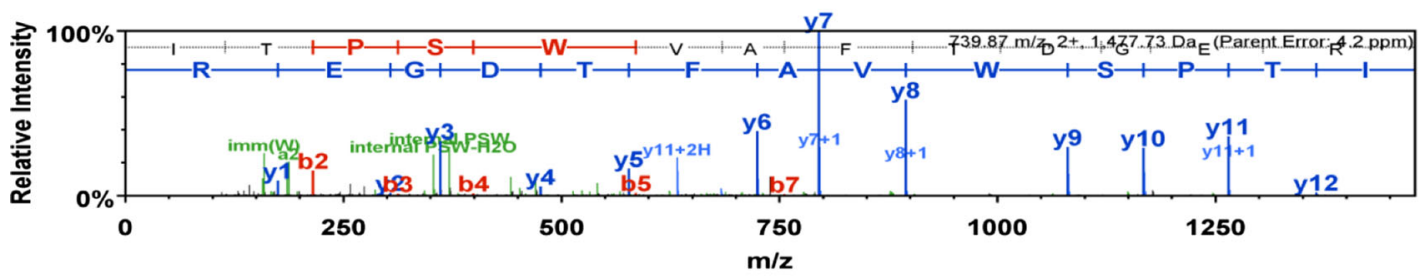

$\mathrm{c}$
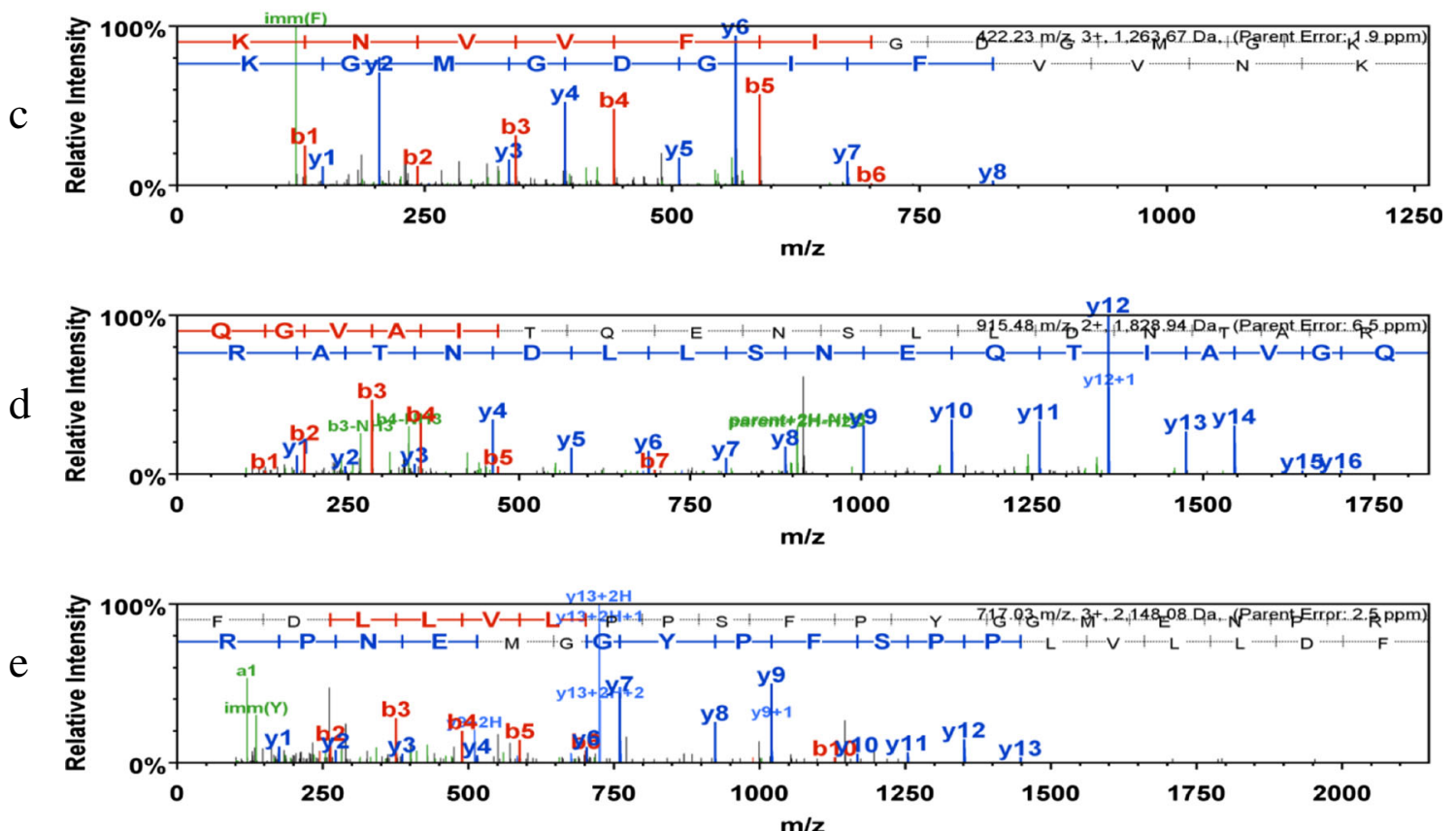

Fig. 5. MS spectra of related proteins determined by LC-MS/MS. A Heat shock 70-kDa protein (HSP70_MAIZE). B Luminal-binding protein (BIP_SPIOL). C Probable pectin esterase (PME64_ARATH). D Glucose-6-phosphate isomerase 1 (G6PIP_ARATH). EUDP-sugar pyrophosphorylase (USP_ORYSJ).

Recent studies have shown that SCIT may effectively alleviate allergy symptoms [14, 20,21], but there is no evidence as to whether the efficacy will last long term in mice. The clinical efficacy of immunotherapy is associated with symptom relief and immune homeostasis. After SCIT, the mice were re-challenged with $0.1 \%$ birch pollen aerosol to observe the immune response. We found that specific immunotherapy has a long-term therapeutic benefit.

Cytokines in BALF are measured by xMAP technology on the basis of the high flux multifactor test platform
Luminex200 TM Merck Millipore (USA) together with Luminex ${ }^{\circledR}$ is applied in many studies to detect biomarkers [22-25]. We monitored the changes of IFN- $\gamma$, IL4, IL5, IL6, IL10, IL17, and TGF- $\beta$ during the process of BPE SCIT, to find response biomarkers of birch pollen immunotherapy. Obviously, we need further studies to elucidate the immunologic mechanisms of these cytokines and their biological effects on immune cells.

We found that a $70-\mathrm{kDa}$ protein played a role in a birch pollen mouse model. To gain insight into the 
protein content, we evaluated the protein in extracts of pollen of Chinese origin by MS-based proteomics. The heat shock protein 70 (Hsp 70) family is considered unglycosylated and exhibits an oral allergy syndrome to plant foods [26]. For example, luminal binding protein (BiP) belongs to the Hsp 70 family and plays an important role in protein synthesis and in the protection of cellular structures [27, 28]. This protein has cross-reactive homologs in many plant tissues and species and is recognized as a panallergen [1].

Our study has many limitations. On the one hand, the luminal binding protein (BiP) is just verified in birch pollen-induced mice models not in human serums, which will be improved by our laboratory in the further studies. On the other hand, we ignored to observe parts of the cytokines (IFN-gama, IL-4, IL-10, and IL-17) in BALF of long-term observation group. In that group, we focus more on the efficacy of SCIT (such as the level of AHR and sIgE) than the change of cytokines.

In conclusion, we established the first mice model of Chinese birch pollen allergy and administered Chinese birch pollen-specific immunotherapy. We compared the efficacy of SCIT with or without adjuvant alum. Moreover, a $70-\mathrm{kDa}$ protein belonging to the Hsp 70 family may play a role in Chinese birch pollen allergy.

\section{AUTHORSHIP AND CONTRIBUTION}

Zhijuan Xie and Jia Yin performed the study, analyzed and interpreted the data, and wrote the manuscript. Zhijuan Xie and Jia Yin contributed to acquisition of data and manuscript preparation and revision. All authors approved the final version of the manuscript.

\section{FUNDING INFORMATION}

This study was funded by grants from the CAMS Innovation Fund for Medical Sciences (No. 2016-I2M-1003) and the Natural Science Foundation of China (No. 81273277).

\section{COMPLIANCE WITH ETHICAL STANDARDS}

Conflict of Interest. The authors declare that they have no conflict of interest.
Open Access This article is distributed under the terms of the Creative Commons Attribution 4.0 International License (http://creativecommons.org/licenses/by/4.0/), which permits unrestricted use, distribution, and reproduction in any medium, provided you give appropriate credit to the original author(s) and the source, provide a link to the Creative Commons license, and indicate if changes were made.

Publisher's Note Springer Nature remains neutral with regard to jurisdictional claims in published maps and institutional affiliations.

\section{REFERENCES}

1. Erler, A., T. Hawranek, L. Kruckemeier, et al. 2011. Proteomic profiling of birch (Betula verrucosa) pollen extracts from different origins. Proteomics 11 (8): 1486-1498.

2. Kim, M.A., D.K. Kim, H.J. Yang, Y. Yoo, Y. Ahn, H.S. Park, H.J. Lee, Y.Y. Jeong, B.S. Kim, W.Y. Bae, A.S. Jang, Y. Park, Y.I. Koh, J. Lee, D.H. Lim, J.H. Kim, S.M. Lee, Y.M. Kim, Y.J. Jun, H.Y. Kim, Y. Kim, J.H. Choi, and Work Group for Rhinitis, the Korean Academy of Asthma, Allergy and Clinical Immunology. 2018. Pollen-food allergy syndrome in Korean pollinosis patients: a nationwide survey. Allergy, asthma \& immunology research. 10 (6): 648-661.

3. Wagner, A., H. Zielinska-Blizniewska, and W. Wagner. 2018. The incidence of delayed-type hypersensitivity reactions to apples among patients allergic to birch pollen. Allergy, Asthma \& Immunology Research 10 (4): 420-424.

4. Siebeneicher, S., S. Reuter, A. Wangorsch, M. Krause, K. Foetisch, A. Heinz, S. Naito, A. Reuter, C. Taube, S. Vieths, S. Scheurer, and M. Toda. 2015. Epicutaneous immunotherapy with a hypoallergenic Bet $\mathrm{v} 1$ suppresses allergic asthma in a murine model. Allergy 70 (12): $1559-1568$.

5. Ma, W.J., M.J. Bao, J.P. Zhu, H.Y. Yao, Y.C. Xie, Y. Guan, F.F. Li, X.W. Dong, Y.M. Zheng, and Q.M. Xie. 2012. Oral administration of allergen extracts from mugwort pollen desensitizes specific allergen-induced allergy in mice. Vaccine 30 (8): 1437-1444.

6. Kopp, M.V. 2011. Role of immunmodulators in allergen-specific immunotherapy. Allergy 66 (6): 792-797.

7. Radulovic, S., D. Wilson, M. Calderon, and S. Durham. 2011. Systematic reviews of sublingual immunotherapy (SLIT). Allergy 66 (6): 740752.

8. Geroldinger-Simic, M., T. Zelniker, W. Aberer, C. Ebner, C. Egger, A. Greiderer, N. Prem, J. Lidholm, B.K. Ballmer-Weber, S. Vieths, and B. Bohle. 2011. Birch pollen-related food allergy: clinical aspects and the role of allergen-specific $\mathrm{IgE}$ and $\mathrm{IgG} 4$ antibodies. The Journal Of Allergy And Clinical Immunology 127 (3): 616-622 e611.

9. Pichler, U., C. Asam, R. Weiss, et al. 2013. The fold variant BM4 is beneficial in a therapeutic Bet v 1 mouse model. BioMed Research International 2013: 832404.

10. Groux, H., A. O'Garra, M. Bigler, M. Rouleau, S. Antonenko, J.E. de Vries, and M.G. Roncarolo. 1997. A CD4+ T-cell subset inhibits 
antigen-specific T-cell responses and prevents colitis. Nature 389 (6652): 737-742.

11. Kimura, A., and T. Kishimoto. 2010. IL-6: regulator of Treg/Th17 balance. European Journal of Immunology 40 (7): 1830-1835.

12. Zimmer, J., S. Doring, D. Strecker, et al. 2017. Minor allergen patterns in birch pollen allergen products-a question of pollen? Clinical and experimental allergy: journal of the British Society for Allergy and Clinical Immunology. 47 (8): 1079-1091.

13. Gonzalez-Mancebo, E., D. Gonzalez-de-Olano, M.J. Trujillo, et al. 2011. Prevalence of sensitization to lipid transfer proteins and profilins in a population of 430 patients in the south of Madrid. Journal of Investigational Allergology \& Clinical Immunology 21 (4): 278-282.

14. van Rijt, L.S., L. Gouveia, A. Logiantara, D. Canbaz, D.J. Opstelten, H.P.M. van der Kleij, and R. van Ree. 2014. Birch pollen immunotherapy in mice: inhibition of Th2 inflammation is not sufficient to decrease airway hyper-reactivity. International Archives of Allergy and Immunology 165 (2): 128-139.

15. Deng, Y.M., Q.M. Xie, H.F. Tang, J.G. Sun, J.F. Deng, J.Q. Chen, and S.Y. Yang. 2006. Effects of ciclamilast, a new PDE 4 PDE4 inhibitor, on airway hyperresponsiveness, PDE4D expression and airway inflammation in a murine model of asthma. European Journal of Pharmacology 547 (1-3): 125-135.

16. Cao, R., X.W. Dong, J.X. Jiang, X.F. Yan, J.S. He, Y.M. Deng, F.F. Li, M.J. Bao, Y.C. Xie, X.P. Chen, and Q.M. Xie. 2011. M(3) muscarinic receptor antagonist bencycloquidium bromide attenuates allergic airway inflammation, hyperresponsiveness and remodeling in mice. European Journal of Pharmacology 655 (1-3): 83-90.

17. Laemmli, U.K., F. Beguin, and G. Gujer-Kellenberger. 1970. A factor preventing the major head protein of bacteriophage T4 from random aggregation. Journal of Molecular Biology 47 (1): 69-85.

18. Halken, S., D. Larenas-Linnemann, G. Roberts, M.A. Calderón, E. Angier, O. Pfaar, D. Ryan, I. Agache, I.J. Ansotegui, S. Arasi, G. du Toit, M. Fernandez-Rivas, R. Geerth van Wijk, M. Jutel, J. KleineTebbe, S. Lau, P.M. Matricardi, G.B. Pajno, N.G. Papadopoulos, M. Penagos, A.F. Santos, G.J. Sturm, F. Timmermans, R. van Ree, E.M. Varga, U. Wahn, M. Kristiansen, S. Dhami, A. Sheikh, and A. Muraro. 2017. EAACI guidelines on allergen immunotherapy: prevention of allergy. Pediatric Allergy and Immunology 28 (8): 728-745.

19. Utsch, L., A. Logiantara, M. Wallner, H. Hofer, R. van Ree, and L.S. van Rijt. 2016. Birch pollen immunotherapy inhibits anaphylaxis to the cross-reactive apple allergen Mal d 1 in mice. Clinical and experimental allergy: journal of the British Society for Allergy and Clinical Immunology. 46 (11): 1474-1483.

20. Feuille, E., and A. Nowak-Wegrzyn. 2018. Allergen-specific immunotherapies for food allergy. Allergy, Asthma \& Immunology Research 10 (3): 189-206.

21. Sohn, M.H. 2018. Efficacy and safety of subcutaneous allergen immunotherapy for allergic rhinitis. Allergy, Asthma \& Immunology Research 10 (1): 1-3.

22. Zhou, S., E.N. Potts, F. Cuttitta, W.M. Foster, and M.E. Sunday. 2011. Gastrin-releasing peptide blockade as a broad-spectrum antiinflammatory therapy for asthma. Proceedings of the National Academy of Sciences of the United States of America 108 (5): 2100-2105.

23. Miethke, A.G., V. Saxena, P. Shivakumar, G.E. Sabla, J. Simmons, and C.A. Chougnet. 2010. Post-natal paucity of regulatory T cells and control of NK cell activation in experimental biliary atresia. Journal of Hepatology 52 (5): 718-726.

24. Golias, J., M. Schwarzer, M. Wallner, M. Kverka, H. Kozakova, D. Srutkova, K. Klimesova, P. Sotkovsky, L. Palova-Jelinkova, F. Ferreira, and L. Tuckova. 2012. Heat-induced structural changes affect OVA-antigen processing and reduce allergic response in mouse model of food allergy. PLoS One 7 (5): e37156.

25. Agache, I., and L. Rogozea. 2017. Asthma biomarkers: do they bring precision medicine closer to the clinic? Allergy, Asthma \& Immunology Research 9 (6): 466-476.

26. Gruehn, S., C. Suphioglu, R.E. O'Hehir, and D. Volkmann. 2003. Molecular cloning and characterization of hazel pollen protein $(70 \mathrm{kD})$ as a luminal binding protein $(\mathrm{BiP})$ : a novel cross-reactive plant allergen. International Archives of Allergy and Immunology 131 (2): 91-100.

27. Miernyk, J.A. 1999. Protein folding in the plant cell. Plant Physiology 121 (3): 695-703.

28. Vitale, A., and J. Denecke. 1999. The endoplasmic reticulumgateway of the secretory pathway. The Plant Cell 11 (4): 615-628. 